\title{
Study on Rheological property of SBS Modified Asphalt Mortar Combining Burgers Model
}

\author{
Peng Cui ${ }^{1, a}$, Yunjuan Yuan ${ }^{2, b}$, Teng Wang ${ }^{2, c}$, Gang Tan ${ }^{3, d}$, Junjun Geng ${ }^{2, e}$, Min \\ Zhou ${ }^{2, f}$, Haobo Hou ${ }^{2, g}$, Yongjie Xue ${ }^{3, h, *}$ \\ ${ }^{1}$ Tongliao City Traffic Bureau, TongLiao, China \\ ${ }^{2}$ School of Resource and Environment Science, Wuhan University, Wuhan, China \\ ${ }^{3}$ State Key Laboratory of Silicate Materials for Architectures, Wuhan University of Technology, \\ Wuhan, China
}

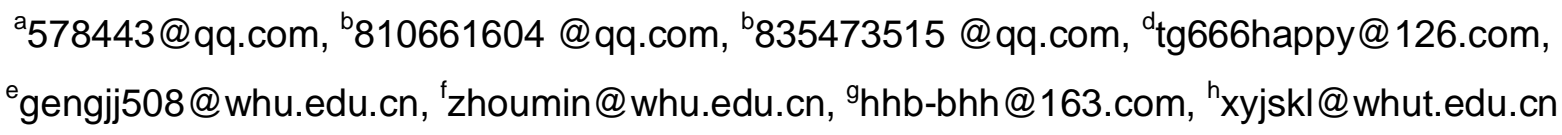

Keywords: Asphalt mortar, Rheological property, Burgers model.

Abstract. Rheological characteristics of bitumen can describe the resistance of bitumen to temperature variation and traffic loading well, which is linked to the in-service behavior of actual bituminous pavement. Modern theory of mortar denotes the study on rheological property of mortar is an important role to study asphalt system. This paper studies the rheological properties of base bitumen, SBS modified asphalt and SBS mortar using Dynamic Shear Rheometer (DSR). The results show that SBS has a better high and low temperature performance and fatigue property than base asphalt. The addition of filler improves high temperature performance of asphalt, but reduces low temperature performance and fatigue property. In addition, Second-order Burgers can well describe the viscoelastic property of SBS mortar.

\section{Introduction}

Bitumen is a viscoelastic material that possesses the abilities of both viscous flow and elastic deformation, so the rheological characteristics of bitumen are very sensitive to temperature and loading rate $[1,2]$. Generally, the binder tends to suffer flowing deformation at high temperature but plastic deformation at low temperature [3]. Dynamic shear rheometer(DSR) test used to measure the linear viscoelastic region of bitumen in the sinusoidal (oscillatory) loading mode is effective in investigating bitumen rheology according to the strategic highway research program (SHRP). The linear viscoelastic region obtained from the DSR can describe the resistance of bitumen to temperature variation and traffic loading well, which is linked to the in-service behavior of actual bituminous pavement [4].

Modern theory of motar consider that asphalt mixture is a kind of multi-level space mesh gel structure system of dispersion: Asphalt mixture with coarse aggregate as the dispersing phase disperse in the asphalt grout, asphalt grout with fine aggregate as the dispersing phase disperse in the asphalt motar, asphalt motar with filler as the dispersing phase disperse in the asphalt [5].Asphalt mortar is the most important feature in modern theory of motar, it is actually as binder in the mixture. Asphalt mortar plays an important role to pavement performance of the mixtures. Hence the study on rheological properties of asphalt mortar becomes worthwhile $[6,7]$.

This paper studies the rheological properties of 70\# base bitumen, SBS modified asphalt and SBS mortar using Dynamic Shear Rheometer (DSR). Temperature sweep test and frequency weep 
test were adopted to evaluate high and low temperature performances and fatigue performance of base asphalt, SBS modified asphalt and SBS motar. Creep and relaxation test was used to express rheologic behavior combining Second-order Burgers model. In addition, the influence of filler on rheological properties of asphalt was studied, in order to provide guidance for pavement performance of mixture.

\section{Materials}

This paper chooses 70\# base asphalt and SBS (I-C) asphalt as research objects. Limestone is used as filler, and its apparent specific gravity is $2.702 \mathrm{~g} / \mathrm{cm}^{3}$. Asphalt-filler radio is $1: 1$. The basic performance of raw materials is shown in Table 1.

Table 1 Physical properties of asphalt

\begin{tabular}{ccc}
\hline Test item & SBS & $70 \#$ \\
\hline Penetration $\left(25^{\circ} \mathrm{C} 、 100 \mathrm{~g} 、 5 \mathrm{~s}\right)(0.1 \mathrm{~mm})$ & 62 & 73.5 \\
Softening point (ring-and-ball test $)\left({ }^{\circ} \mathrm{C}\right)$ & 74 & 49 \\
Ductility $(5 \mathrm{~cm} / \mathrm{min})(\mathrm{cm})$ & $61^{\mathrm{a}}$ & $\geq 150^{\mathrm{b}}$ \\
Flash point $\left({ }^{\circ} \mathrm{C}\right)$ & 265 & $\geq 230$ \\
\hline
\end{tabular}

a: experimental temperature is $5^{\circ} \mathrm{C}$; b: experimental temperature is $15^{\circ} \mathrm{C}$

\section{Experiment}

Dynamic rheological characterization

Dynamic Shear Rheometer (DSR) MCR101 from Austria Anton Paar Company was used in this study for generating the dynamic data for the bitumen and bitumen mortar.

\section{Results and discussion}

\section{Temperature sweep test}

In accordance with the SHRP specification, $\mathrm{G}^{*} / \sin \delta$ is defined as the rutting factor that can be selected to estimate the contribution of a binder to the permanent deformation at high temperatures. Higher value of $\mathrm{G}^{*} / \sin \delta$ implies a better resistance of bitumen to rutting deformation.

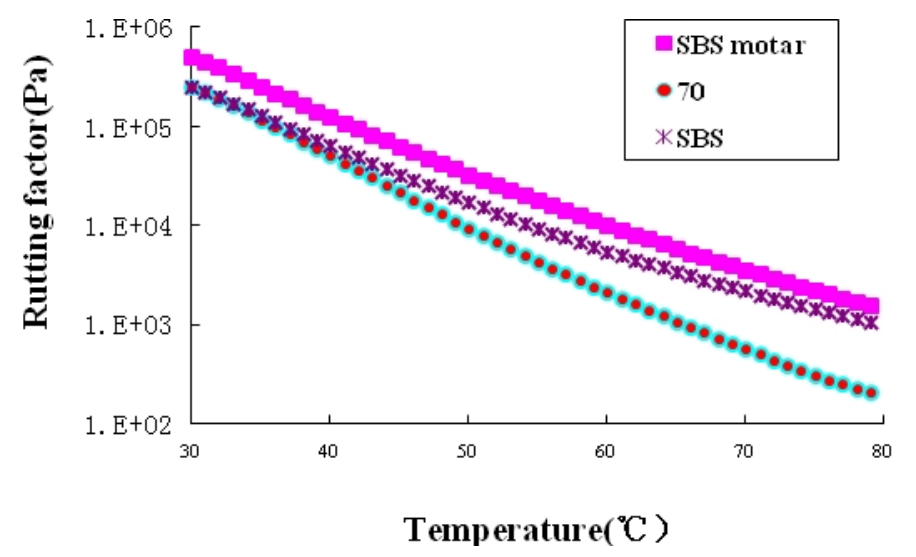

Fig 1 Rutting factor $(\mathrm{G} * / \sin \delta)$ of bitumens and mortar

In SHRP specification, the temperature of the fresh binders when $G^{*} / \sin \delta$ is equal to $1 \mathrm{kPa}$ is a 
criterion for the verification of performance grade of a bitumen. As illustrated in Table 2, the resulting temperature is $80.2^{\circ} \mathrm{C}, 76.7^{\circ} \mathrm{C}$ and $49.6^{\circ} \mathrm{C}$ for the SBS motar, SBS modified asphalt and base bitumen respectively.

Table 2 Critical temperature of different asphalt

\begin{tabular}{cc}
\hline Types of asphalt & $\mathrm{G}^{*} / \sin \delta=1 \mathrm{kPa}\left({ }^{\circ} \mathrm{C}\right)$ \\
\hline SBS motar & 80.2 \\
SBS & 76.7 \\
$70 \#$ & 49.6 \\
\hline
\end{tabular}

Learning from Fig.1 and Table 2, SBS has a better resistance rutting deformation, and the high-temperature performance of bitumen is improved with the addition of filler.

According to the SHRP, the fatigue factor $\left(\mathrm{G}^{*} \cdot \sin \delta\right)$ can be used to evaluate the fatigue properties of bitumen. The higher the $G^{*} \cdot \sin \delta$ value, the more quickly the shearing energy dissipates under load, namely, the worse fatigue resistant ability the bitumen has.

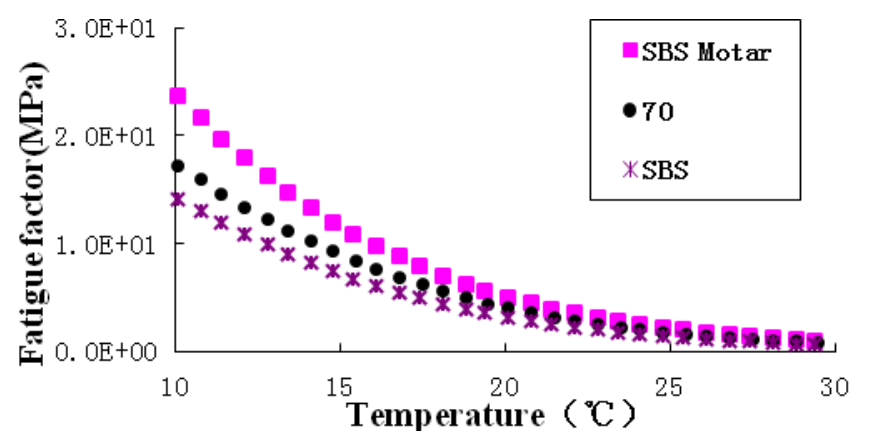

Fig 2 Fatigue factor $\left(\mathrm{G}^{*} \cdot \sin \delta\right)$ of bitumens and mortar

Due to the fatigue damage of asphalt generally appearing at medium temperature, therefore temperature range $\left(10-30^{\circ} \mathrm{C}\right)$ is selected to evaluate the fatigue performance. Obviously, SBS has a better fatigue restraint ability according to Fig.2. And the addition of filler breaks the fatigue resistance performance.

\section{Frequency weep test}

Master curves are constructed by shifting the rheological data to a reference temperature of 20 ${ }^{\circ} \mathrm{Cusing}$ Arrhenius formula as previous research introducing. Fig.3, 4 show the master curves of mortar materials at a reference temperature of $20^{\circ} \mathrm{C}$. It shows complex modulus increase with the increase of frequency. According to time-temperature superposition principle, the results indicate that SBS has a bigger modulus at high temperature, meanwhile with a smaller modulus at low temperature. In other words, SBS modified asphalt has a better high and low temperature performance. The Fig 3 can also show that the addition of filler can increase the temperature sensitivity of the material. It will harm pavement performance of material. 


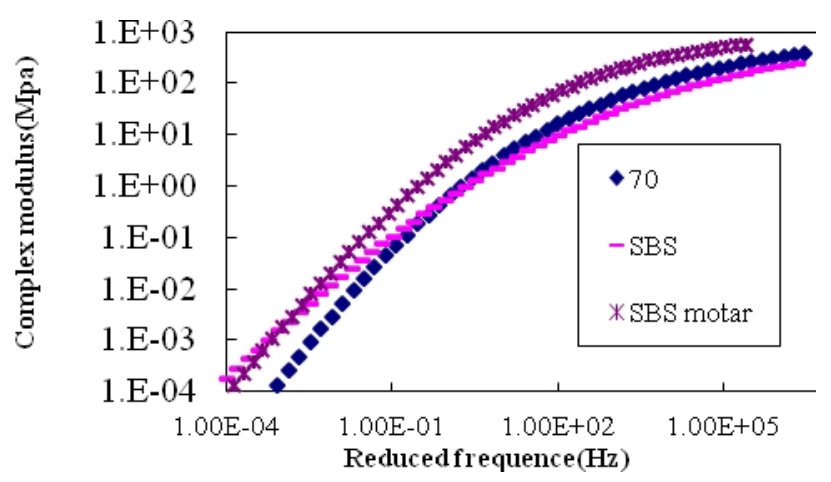

Fig 3 Master curves of asphalts and mortar at reference temperature of $20{ }^{\circ} \mathrm{C}$

Learning from Fig.4, SBS modified asphalt the mortar have platform at middle frequence. It certifies the existence of SBS polymer. Comparing with base asphalt, SBS has a smaller phase angel in the whole frequency range. It means SBS modified asphalt possess a better elasticity. Filler gives more viscous component to SBS, but it's still better than base asphalt.

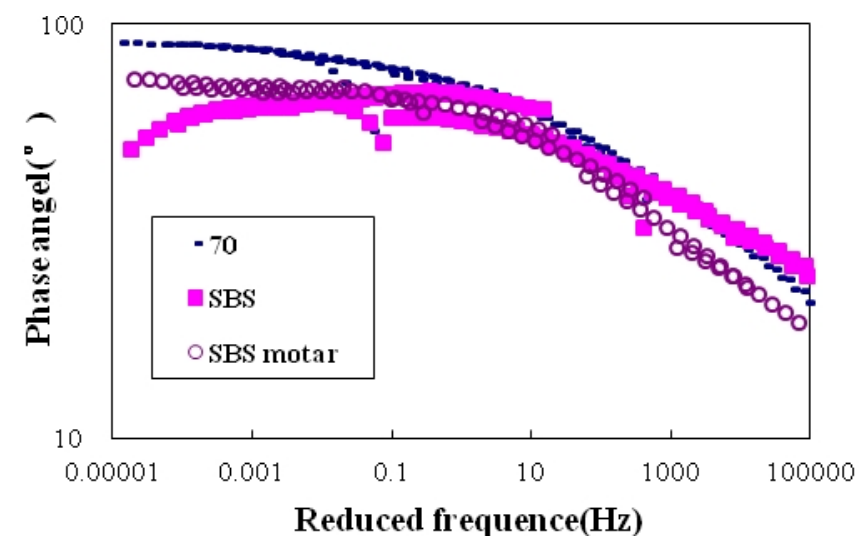

Fig 4 Master curves of asphalts and mortar at reference temperature $\left(20^{\circ} \mathrm{C}\right)$

\section{Burgers model}

A large number of experimental data show that the fitting results of Bugers model have a good corresponding relation with the actual result, especially in the loading period. The model can express viscoelastic of bitumens accurately. Order of the model only influences the distribution of elastic modulus and damping coefficient in viscoelastic component. The bigger order numbers always represent the greater degree of fitting between fitting results and the measured results.
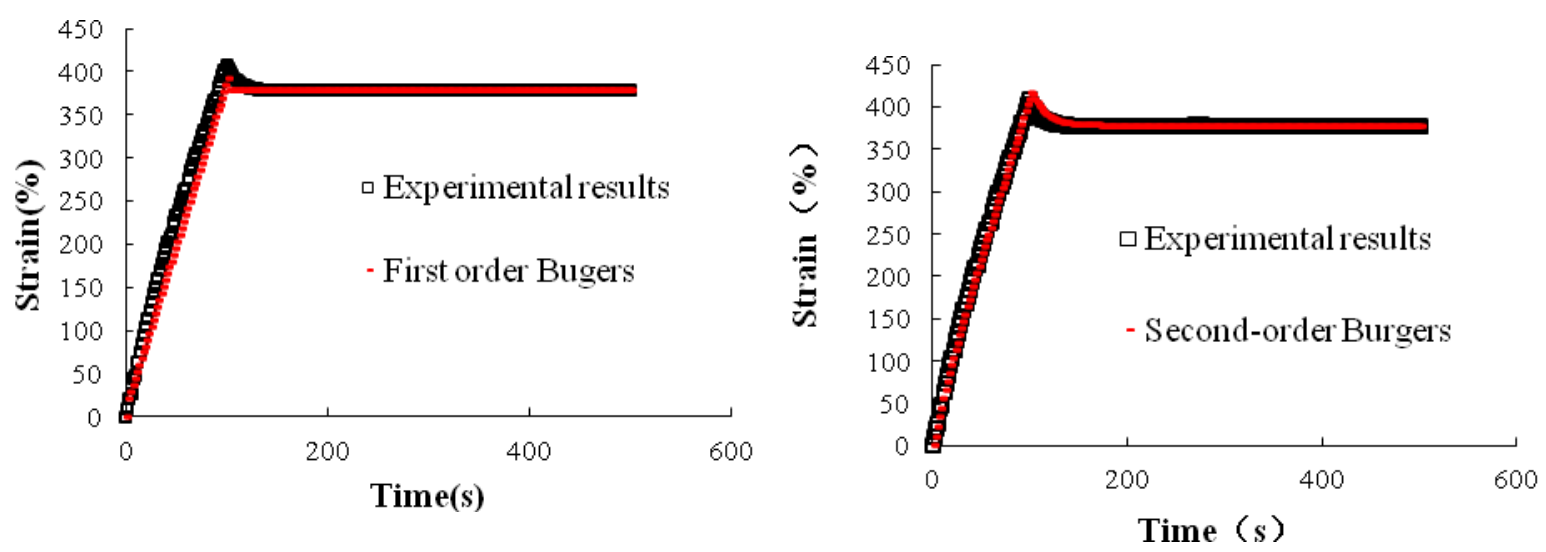

Fig 5 Establishment of Burgers model of SBS motar at $60^{\circ} \mathrm{C}$ 
Table 3 error analysis of Burgers model

\begin{tabular}{cc}
\hline Order Number & Error (\%) \\
\hline 1 & 2.849 \\
2 & 0.608 \\
\hline
\end{tabular}

As shown in Fig 5 and Table 3, when study SBS mortar, fitting deviation of first-order Burgers model is significantly great, especially in unloading period. Second-order Burgers can well describe the viscoelastic property of SBS mortar.

\section{Conclusions}

Based on the laboratory test results and the analysis made in this paper, the following conclusions can be obtained.

SBS has a better resistance rutting deformation than base asphalt, and the high-temperature performance of bitumen is improved with the addition of filler.

SBS has a better fatigue restraint ability than base asphalt. Fatigue resistance performance of SBS bitumen reduces with addition of filler.

The addition of filler harms pavement performance of SBS. And SBS modified asphalt has a better high and low temperature performance than 70\# base asphalt even in the case of filler occupying half the mass of mortar.

Second-order Burgers can well describe the viscoelastic property of SBS mortar.

\section{Acknowledgements}

The experiment is supported by State Key Laboratory of Silicate Materials for Architectures, Wuhan University of Technology. The authors gratefully acknowledges their financial and apparatus support.

\section{References}

[1] S. Lalwani, A. Abushihada, and A.Halasa, Reelaimed Rubber-Asphalt Blends Measurement of Rheological Properties to Assess Toughness, Resilieney, Consistensy, and Temperature Sensitivity,Journal of the Association of Asphalt Paving Technologists,Vol51,562-579,1982.

[2] Dimitrios G.Goulias, Use of Tire Rubber in Hot Mix Asphalt:Binder and Mixture Evaluation,Journal of Solid Waste Technology and Management,24(3),1997,121-125.

[3] Francoise Durrieu, Fabienne Farcas, Virginie Mouillet. Fuel,2007,86:1446-1451.

[4] Chunfa Ouyang, Shifeng Wang,Yong Zhang,et al. Fuel, 2006, 85:1060-1066.

[5] Witczak T W, Bari J, and Quayum M. National Cooperative Highway Research Program, Rep. No. 9-19: Superpave support and performance models management, field validation of the simple performance test[R].Arizona State Univ, Tempe, AZ,2003.

[6] Navarro F J, Partal P, Martinez B F,et al. Chemical Engineering Journal ,2002,89 :50-61.

[7] Aflaki S, Milad M.Construction and Building Materials, 2011, 25: 2777-2784.

[8] BahiaH.U.,ZhaiH.,KoseH.,etal..Journal of the Assoeiation of Asphalt Paving Technologists, 1999,68:1-34.

[9] Menglan Zeng Hussain U. Bahia Huachun Zhai etl. Journal of the Association of Asphalt 
Paving Technologists. 2001,70: 403-435.

[10] Ghuzlan,K.A., and S.H.Carpenter. In Transp. Res. Rec. 1723, TRB, Washington,D.C., 2000: 141-149

[11]Anderson, D.A., Bahia, H.U., Dongre, Raj.ASTM Special Technical Publication, 1992:131-153. 